\title{
Measurement the Levels of Catalase Activity, Malondialdehyde and Ferritin in Beta-thalassemia Major Patient
}

\author{
Abdalaziz Ali Shakir ${ }^{1}$, Alaa Mohammad Hasson Al-Husseini² \\ ${ }^{1}$ Research, ${ }^{2}$ Assit. Prof., University of Al-Qadisiyah, College of Science, Department of Biology, Iraq
}

\begin{abstract}
The present study has been carried out at the Women's and Educational Children's Hospital in the city of Samawa to determine the level of oxidative stress indicators and level ferritin. 66 samples of a patient with beta-thalassemia major were collected and observation of some clinical signs was followed, the group of a patient was divided into two subgroups according to the splenectomy, Group One (G1)) Included 52 samples from beta-thalassemia major patients, type non-splenectomy, (G2) included 14 samples from thalassemia patients splenectomy and 34 samples were collected from healthy males as control samples (C) to measure the level the activity of Catalase enzyme (CAT) and concentration levels of malondialdehyde MDA as oxidative stress indicators by using the Spectrophotometer and level ferritin using vidas. The results showed a significant decrease $(p<0.05)$ in the efficacy of catalase and a significant increase $(p<0.05)$ in the level of the MDA and level ferritin in beta-thalassemia major patients compared to control group.
\end{abstract}

Keywords: Beta-thalassemia, splenectomy, MDA, CAT.

\section{Introduction}

Thalassemia: It is a genetic disorder in the synthesis of haemoglobin widespread in the world. The distinguishing feature of thalassemia is the synthesis of unbalanced globin chains, as the synthesis of the $\alpha$-chain takes place at a normal rate, in contrast, a decrease in the production of the $\beta$-chain, which leads to deposits $\mathrm{A}$ large intracellular basis leads to ineffective erythrocyte production and a set of subsequent pathophysiological mechanisms $^{(1)}$. Oxidative stress is a disturbance in the balance between oxidants and antioxidant enzymes present in the body. Oxidative stress occurs in patients with beta-thalassemia major as a result of increased levels of lipid peroxides and intermediate free radicals, as well as a decrease in the total capacity of antioxidants caused by repeated blood transfusions due to severe anemia. The use of iron chelation agents with antioxidants material can be useful in regulating antioxidant status in patients with beta-thalassemia major ${ }^{(2)}$ Perform frequent blood transfusions in patients with beta-thalassemia major, iron levels are increased, making the red blood cells vulnerable to oxidative stress ${ }^{(3)}$ Due to increased generation of free radicals and lipid peroxidation, and a decrease in total antioxidant capacity, lead to an imbalance between oxidants and antioxidants that results in oxidative stress $^{(4)}$ Patients with beta-thalassemia major receive regular blood transfusions monthly to prevent severe anemia and allow the normal growth and development of the body ${ }^{(5)}$. Each unit of donor blood contains $420 \mathrm{ml}$ of blood and about $200 \mathrm{mg}$ of iron ${ }^{(6)}$ While blood transfusions prevent many complications of severe anemia, the body is unable to get rid of the iron overload that accompanies every blood transfusion, so it is deposited in the tissues and organs, leading to damage and failure of the body's systems ${ }^{(7) .}$ By stimulating the formation of reactive oxygen species (ROS) causing chronic oxidative stress the excess quantities of iron convert oxidants into high-energy radicals represented by hydroxyl radicals from ROS through the Fenton/HaberWeiss reaction ${ }^{(8)}$. Which leads to oxidative stress, as ROS acts on lipid peroxidation of free cell membranes to formlipid hydroperoxides, which upon their dissolution form cell-toxic secondary compounds such as alkanes and aldehydes (such as MDA), which is a by product of the lipid peroxidation process, which reflects cases of increased generation of free radicals and Oxidative stress $^{(9)}$. MDA is a biomarker of oxidative damage ${ }^{(10)}$. Also, it is considered one of the indicators of iron concentration in the liver, and chronic blood transfusion in thalassemia patients is associated with the cumulative damage of iron in the tissues ${ }^{(11)}$. The level of MDA in the blood plasma of beta-type thalassemia major patients 
increases (1-8) times compared to healthy subjects ${ }^{(12)}$. Also, the levels of cellular antioxidant vitamins such as vitamins $\mathrm{A}, \mathrm{C}$ and $\mathrm{E}$, and enzymatic antioxidants such as catalase, glutathione peroxide and glutathione in patients with beta-thalassemia major, compared to the normal level for healthy people, indicates the effect of disease on antioxidant systems ${ }^{(13)}$. The presence of the catalase enzyme as an antioxidant system in all cells and at high concentrations in red blood cells works to remove hydrogen peroxide by analyzing it into molecular oxygen and water ${ }^{(14)}$.It is one of the most abundant antioxidants that work to reduce the types of reactive oxygen (ROS) that accompany many diseases such as thalassemia, aging, cataract, atherosclerosis, diabetes and nutritional deficiencies $^{(15)}$.

\section{Materials and Method}

This study was conducted at the College of Science/ Al-Qadisiyah University for the period from 1/10/2019 to $1 / 10 / 2020$, as 66 samples of males with Thalassemia were collected in the Thalassemia Center in Samawah, and they were previously diagnosed, and they were divided into two groups: Group One (G1)) Included 52 samples from beta-thalassemia major patients, type non-splenectomy, and the second group (G2) included 14 samples from Thalassemia patients splenectomy, and 34 samples were collected from non-infected males as control samples (C), with ages ranging from 18 to 40 years for all samples.

Sample collection: About $4 \mathrm{ml}$ of venous blood was drawn by syringe from the current study samples, then transferred to gel tubes without anticoagulant and then left for 20 minutes at room temperature for blood to coagulate, and then transferred to a centrifuge for ten minutes at $3000 \mathrm{rpm}$. Then, collecting and transfer into 3 test tubes to use in measuring the level of ferritin,MDA and CAT.

Measuring the level of ferritin: The serum concentration of ferritin was measured by automated equipment (Vidas). The assay principle combines an enzyme immunoassay competition method with a final fluorescent detection (ELFA). The solid phase receptacle (SRP) serves as the solid phase as well as the pipetting device for the assay. Dispensed in the sealed reagent strips. All assay steps are performed automatically by the instrument. The reaction medium is cycled in and out of the SRP several times. The sample is taken and transferred into the well containing the antigen labelled with alkaline phosphate (conjugate). Competition occurs between the antigen present in the sample and the labelled antigen for specific anti-ferritin antibody coated on the interior of the SRP. During the final detection step, the substrate (4-Methyl-umbelliferyl phosphate) is cycled in and out of the SRP. The conjugated enzyme catalyzes the hydrolysis of this substrate into a fluorescent product (4-Methyl-umbelliferyl) the fluorescence of which is measured at $450 \mathrm{~nm}$.

Measurement of catalase activity: The method (Aebi, 1974) was followed to investigate the level of activity of the enzyme catalase in the blood serum, which depends on the activity of the enzyme in breaking down hydrogen peroxide, and its effectiveness is measured by the lack of absorption of consumed hydrogen peroxide, and the absorbance reading of samples is recorded at a wavelength of $240 \mathrm{~nm}$.

Measurement of the Malondialdehyde level: The level of MDA in the serum was measured using the method used by researchers (Guidet and Shah, 1989). The level of MDA was measured in the serum, and it represents one of the main products of lipid peroxide. The method depends on the interaction between lipid peroxides, mainly the Malondialdehyde, and thiobarbituric acid (TBA) This reaction takes place in an acidic medium and forms a coloured product, as the absorption intensity was measured at $532 \mathrm{~nm}$.

Statistical Analysis: To analyze the results, Graph Prism 7 was used to know the significant differences in the studied criteria included in the current study using one-way analysis of variance (ANOVA). Tukey's multiple comparisons test was used with a probability level of 0.05 to compare the significant differences between the averages of the current study groups.

\section{Results and Discussion}

The catalase activity recorded a significant decrease of $p<0.05$ in the G1 patient group compared to the G2 patient group and the control group, while the last two groups did not record a significant difference between them, $\mathrm{p}>0.05$ (Table 1 and Fig. 1A).

The results recorded a significant increase, $\mathrm{p}<0.05$, in the MDA concentration level in the two groups of patients, G1 and G2, compared to the control group, but when the two groups of patients were compared with each other, they did not show a significant difference $\mathrm{p}>$ 0.05 Table (1) and Figure (1B). 
Table (1) and Figure (1C) show the level of ferritin in the two groups of beta-thalassemia patients without splenectomy (G1) and patients with splenectomy (G2) compared to the control group. The results recorded a significant difference of $p<0.05$ in the level of Ferritin at probability level $\mathrm{p}<0.05$ in the G1 and G2 patient groups compared to the control group.

Table (1) The level of efficacy of CAT $(u / \mathrm{ml})$ and the concentration of MDA ( $\mu$ mole/L) and level Ferritin $(\mathrm{ng} / \mathrm{\mu l})$ in beta-thalassemia major

\begin{tabular}{|l|c|c|c|}
\hline Characteristic & Group G1 & Group G2 & Control \\
\hline Catalase $(\mathrm{U} / \mathrm{ml})$ & $2.426 \pm 0.91 \mathrm{~b}$ & $4.261 \pm 0.61 \mathrm{ab}$ & $5.898 \pm 1.1 \mathrm{a}$ \\
\hline Malondialdehyde $(\mathrm{nmol} / \mathrm{l})$ & $0.278 \pm 0.037 \mathrm{~b}$ & $0.235 \pm 0.026 \mathrm{~b}$ & $0.122 \pm 0.026 \mathrm{a}$ \\
\hline Ferritin $(\mathrm{ng} / \mu \mathrm{l})$ & $3546 \pm 530 \mathrm{~b}$ & $4918 \pm 581 \mathrm{~b}$ & $221.7 \pm 31 \mathrm{a}$ \\
\hline
\end{tabular}

Values represent the means \pm standard error. The different letters indicate a significant difference in the probability level $\mathrm{P}<0.05$ among groups, while The similar letters indicate no significant difference in the probability level $\mathrm{P}>0.05$ among groups,
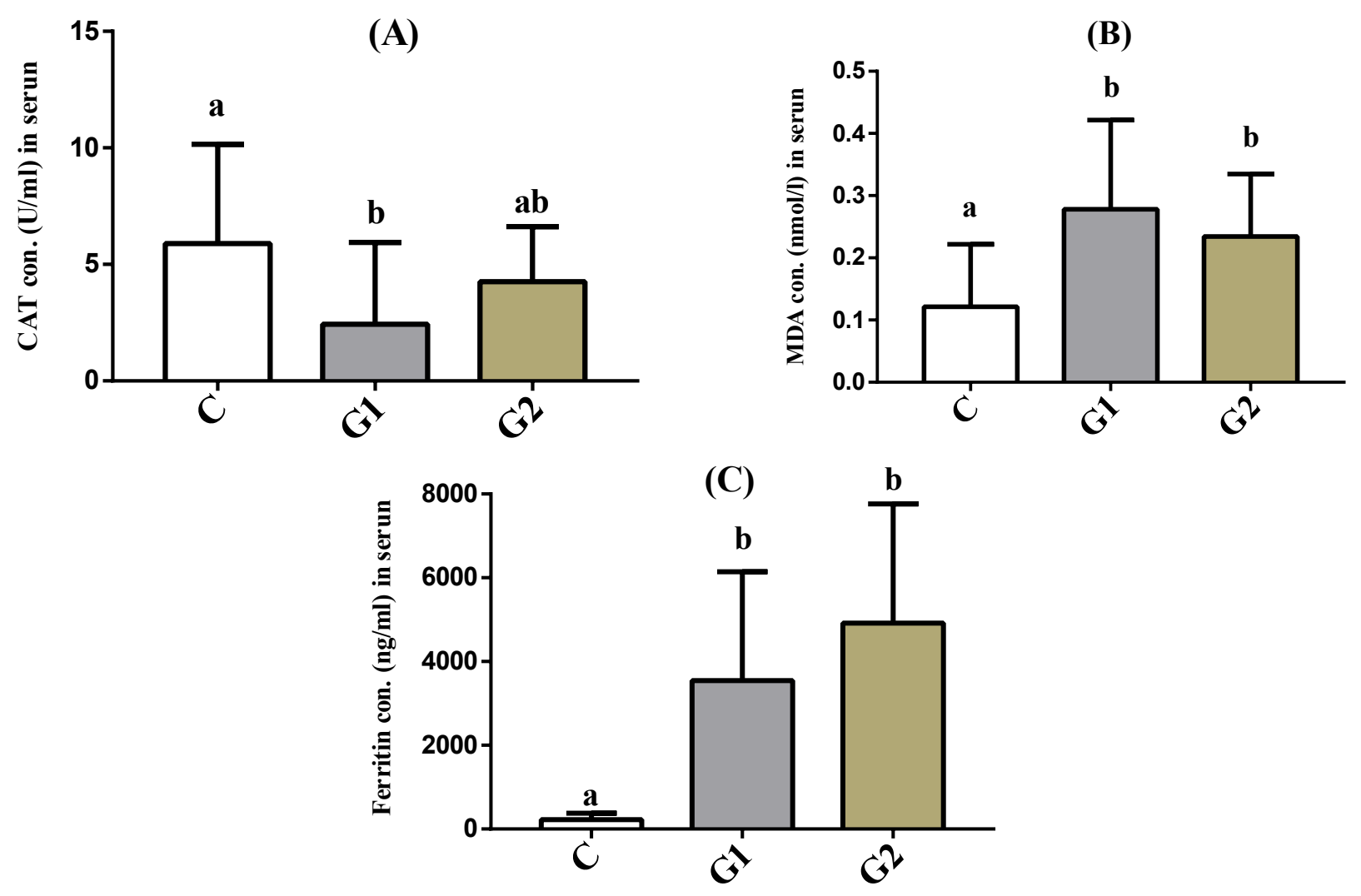

Figure (1) Shows the level of efficacy CAT enzyme (A), MDA concentration (B) and level Ferritin in betathalassemia major.

The decrease in the level of catalase may reflect the extent of oxidative damage that may arise in thalassemia patients, which may be one of the reasons that lead to complications of the disease, as patients suffer from impaired function of the liver, heart, endocrine glands and other clinical complications, as catalase is one of the enzymes of the system Defensive antioxidant in the cells of the body and at a high level in red blood cells. Therefore, the oxidative damage increases when the antioxidant activity decreases against the high 
production of free radicals ${ }^{(16)}$. The decrease in catalase enzyme activity was associated with an increase in the patients' MDA levels, The oxidation of lipids resulting from MDA leads to the generation of collateral bonds that act on some antioxidants and weaken their link with cell membranes, leading to their lack of activity and imbalance of the oxidation-antioxidant system ${ }^{(17) \text {. }}$ Also, thalassemia patients have a low level of expression of the FOXO3 gene, which encodes for antioxidant enzymes, including catalase, and this gene is found spread on red cell membranes, and that the defect and degradation occurring in the patients' blood cells and early stages leads to a decrease in the level of the FOXO3 gene, which is negatively reflected on the antioxidant system and thus inhibition of reactive oxygen species and increase oxidative damage to red blood cells and their membranes ${ }^{(18)}$ and this was confirmed by the AlAthari (2019) study, as it was observed that low levels of catalase activity were associated with decreased expression of the $\mathrm{FOXO} 3$ gene.

The amounts of iron released as a result of the decomposition of hemoglobin in thalassemia patients stimulate the production of reactive oxygen species, in addition to the negative effect resulting from the accumulated iron as a result of periodic blood transfusions to compensate for the decrease in the hemoglobin level, as repeated blood transfusions contribute to increasing iron absorption and thus generating high levels From the reactive oxygen species ROS and superoxide resulting from the increase of free radicals in red blood cells leading to oxidative damage ${ }^{(19)}$ These products increase the lipid peroxidation, which results in high levels of MDA, in addition to that the state of oxidative stress can affect all cells and tissues of the body, and consequently, high levels of MDA in the tissues leak into the blood causing this noticeable increase in thalassemia patients ${ }^{(20)}$ This was confirmed by Walter et al. (2006) in his study, as they observed an increase in the level of MDA in betathalassemia major patients about (1-8) times compared to healthy subjects. As noted by Vichinsky et al. 2005. To the fact that the increase in the level of MDA is one of the indicators of iron concentration in the liver, and the process of chronic blood transfusion in thalassemia patients is associated with the cumulative damage to iron in the tissues, and accordingly, the increased levels of MDA were associated with increased levels of ferritin in patients ${ }^{(21)}$ and these results were consistent with the findings of the current study.

Ferritin binds to iron, transports and stores it in a non-toxic, soluble form. The reason for the increase in ferritin levels may be due to the increase in iron levels caused by thalassemia, or due to frequent blood transfusions in thalassemia patients that lead to rapid iron loading. Because each unit of blood contains 200$250 \mathrm{mg}$ of iron ( $1 \mathrm{ml}$ of red blood cells contains $1 \mathrm{mg}$ of iron) that cannot be excreted ${ }^{(22)}$.Excess iron stimulates lipid oxidation and the generation of oxidants that affect the red blood cells and thus reduce antioxidants, especially catalase, according to what Aziz and others (2017), as he mentioned in his study that iron overload comes from continuous blood transfusions for patients as free iron ions accumulate That leads to an increase in oxidative stress that depletes antioxidants in the cells and thus increased oxidants that cause damage to the membranes and organelles of the cells of the body.Iron also increases in the body as a result of iron absorption in food through the intestine or from continuous blood transfusions, which leads to an accumulation of iron that may exceed the ability to detoxify ferritin ${ }^{(23)}$. One of the secondary causes of iron overload is the inefficiency of the treatments used to iron chelation, accumulated which is one of the main reasons for the increase in oxidants that break down the red blood cells' membranes in their formation stages. ${ }^{(24) \text {. }}$

\section{Ethical Clearance: Nil}

\section{Source of Funding: Self}

\section{Conflict of Interest: Nil}

\section{Reference}

1. Thein, S. L.. Molecular basis of $\beta$ thalassemia and potential therapeutic targets. Blood Cells, Molecules, and Diseases, (2018);70, 54-65.

2. Ghone, R. A., Kumbar, K. M., Suryakar, A. N., Katkam, R. V., \& Joshi, N. G. Oxidative stress and disturbance in antioxidant balance in beta thalassemia major. Indian Journal of Clinical Biochemistry, (2008);23(4), 337-340.

3. Naithani, R., Chandra, J., Bhattacharjee, J., Verma, P., \& Narayan, S. Peroxidative stress and antioxidant enzymes in children with $\beta$-thalassemia major. Pediatric blood \& cancer, (2006); 46(7), 780-785.

4. Pavlova, L. E., Savov, V. M., Petkov, H. G., \& Charova, I. P. Oxidative stress in patients with beta-thalassemia major. Prilozi, (2007); 28(1), 145154. 
5. Azami, M., Gheisoori, A., Sayehmiri, F., \& Sayehmiri, K. Prevalence of hypothyroidism in patients with Beta thalassemia major in Iran: A systematic review and meta-analysis. Scientific Journal of Kurdistan University of Medical Sciences, (2016); 21(1), 104-116.

6. Prabhu, R., Prabhu, V., \& Prabhu, R. S. Iron overload in beta thalassemia: a review. J Biosci Tech, (2009); 1(1), 20-31.

7. Lazarte, S. S., Mónaco, M. E., Terán, M. M., Haro, A. C., Achem, M. E. L., \& Issé, B. A. Foxo3 gene expression and oxidative status in beta-thalassemia minor subjects. Revistabrasileira de hematologia e hemoterapia, (2017);39(2), 115-121.

8. Lobo, V., Patil, A., Phatak, A., \& Chandra, N. Free radicals, antioxidants and functional foods: Impact on human health. Pharmacognosy reviews, (2010); 4(8), 118.

9. Meral, A., Tuncel, P., Sürmen-Gür, E., Özbek, R., Öztürk, E., \& GÜnay, Ü. LIPID PEROXIDATION AND ANTIOXIDANT STATUS IN B-THALASSEMIA. Pediatric hematology and oncology, (2000); 17(8), 687-693.

10. Vichinsky, E., Butensky, E., Fung, E., Hudes, M., Theil, E., Ferrell, L., ... \& Harmatz, P. Comparison of organ dysfunction in transfused patients with SCD or $\beta$ thalassemia. American journal of hematology, (2005); 80(1), 70-74.

11. Walter, P. B., Fung, E. B., Killilea, D. W., Jiang, Q., Hudes, M., Madden, J., ... \& Harmatz, P. Oxidative stress and inflammation in iron-overloaded patients with $\beta$-thalassaemia or sickle cell disease. British journal of haematology, (2006); 135(2), 254-263.

12. Cheng, M. L., Ho, H. Y., Tseng, H. C., Lee, C. H., Shih, L. Y., \& Chiu, D. T. Y. Antioxidant deficit and enhanced susceptibility to oxidative damage in individuals with different forms of $\alpha$-thalassaemia. British journal of haematology, (2005); 128(1), 119-127.

13. Olson, K. R., Gao, Y., DeLeon, E. R., Arif, M., Arif, F., Arora, N., \& Straub, K. D. Catalase as a sulfidesulfur oxido-reductase: an ancient (and modern?) regulator of reactive sulfur species (RSS). Redox biology, (2017);12, 325-339.
14. Scott, M. D. $\mathrm{H} 2 \mathrm{O} 2$ injury in $\beta$ thalassemic erythrocytes: protective role of catalase and the prooxidant effects of GSH. Free Radical Biology and Medicine, (2006);40(7), 1264-1272.

15. Vendemiale, G., Grattagliano, I., \& Altomare, E. An update on the role of free radicals and antioxidant defense in human disease. International Journal of Clinical and Laboratory Research, (1999);29(2), 49.

16. Aebi, H. Catalase. In Method of enzymatic analysis . Academic press, (1974); pp. 673-684 .

17. Guidet, B. E. \& Shah, S. V. Enhanced in vivo $\mathrm{H} 2 \mathrm{O} 2$ generation by rat kidney in glycerol-induced renal failure. American Journal of Physiology-Renal Physiology, (1989);257(3), F440-F445.

18. Maskoen, A. M., Sumantri, N. I., \& Reniarti, L «Enzymatic Antioxidants Activity in Beta Thalassemia Major.» International Journal of ChemTech Research, (2017);10(7):129-134.

19. Mahdi, E. A. Comparison Between Zinc, Copper and Iron Levels in Children with Beta Thalassemia Major And healthy Individuals in Najaf City. AlQadisiyah Journal Of Pure Science, (2014); 19(4), 50-60.

20. Beckman, K. B., \& Ames, B. N. The free radical theory of aging matures. Physiological reviews, (1998).

21. Cighetti, G., Duca, L., Bortone, L., Sala, S., Nava, I., Fiorelli, G., \& Cappellini, M. D. Oxidative status and malondialdehyde in $\beta$-thalassaemia patients. European journal of clinical investigation, (2002);32, 55-60.

22. Ponka, P., Beaumont, C., \& Richardson, D. R. Function and regulation of transferrin and ferritin. In Seminars in hematology,(1998); Vol. 35, No. 1, pp. 35-54.

23. Asif, M., Manzoor, Z., Farooq, M. S., Kanwal, A., Shaheen, U., Munawar, S. H., ... \& Aziz, A. Correlation between serum ferritin level and liver function tests in thalassemic patients receiving multiple blood transfusions. International Journal of Research in Medical Sciences, (2014); 2(3), 988. 